This is the final peer-reviewed accepted manuscript of

Currie, Philip J.; Wilson, Jeffrey A.; Fanti, Federico; Mainbayar, Buuvei; Tsogtbaatar, Khishigjav: Rediscovery of the type localities of the Late Cretaceous Mongolian sauropods Nemegtosaurus mongoliensis and Opisthocoelicaudia skarzynskii: Stratigraphic and taxonomic implications. PALAEOGEOGRAPHY

PALAEOCLIMATOLOGY PALAEOECOLOGY, 494. 0031-0182

DOI: $10.1016 /$ j.palaeo.2017.10.035

The final published version is available online at:

http://dx.doi.org/10.1016/j.palaeo.2017.10.035

Rights / License:

The terms and conditions for the reuse of this version of the manuscript are specified in the publishing policy. For all terms of use and more information see the publisher's website.

This item was downloaded from IRIS Università di Bologna (https://cris.unibo.it/)

When citing, please refer to the published version. 


\title{
Rediscovery of the type localities of the Late Cretaceous Mongolian sauropods Nemegtosaurus mongoliensis and Opisthocoelicaudia skarzynskii: Stratigraphic and taxonomic implications
}

\author{
Philip J. Currie ${ }^{\mathrm{a}, *}$, Jeffrey A. Wilson ${ }^{\mathrm{b}}$, Federico Fanti ${ }^{\mathrm{c}}$, Buuvei Mainbayar ${ }^{\mathrm{d}}$, \\ Khishigjav Tsogtbaatar ${ }^{\mathrm{d}}$

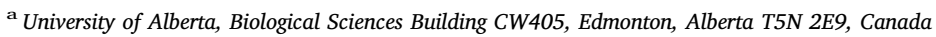 \\ ${ }^{\mathrm{b}}$ Museum of Paleontology and Department of Earth \& Environmental Sciences, University of Michigan, 1109 Geddes Avenue, Ann Arbor, MI 48109-1079, USA \\ ${ }^{\mathrm{c}}$ Dipartimento di Scienze Biologiche, Geologiche e Ambientali, University of Bologna, Via Zamboni 67, 40126 Bologna, Italy \\ d Institute of Paleontology and Geology, Academy of Sciences of Mongolia, P.O.B: 46/650, Ulaanbaatar, Mongolia
}

A R T I C L E I N F O

Keywords:

Upper cretaceous

Nemegt formation

Baruungoyot formation

Sauropoda

Titanosauria

\begin{abstract}
A B S T R A C T
In 1965, the Polish-Mongolian Palaeontological Expeditions recovered two sauropods from the Nemegt Formation of the Nemegt Basin, Mongolia (Kielan-Jaworowska and Dovchin 1968). One specimen, a nicely preserved, complete skull that in 1971 became the holotype of Nemegtosaurus mongoliensis, was found in Central Sayr at the Nemegt Locality. The other was found at Altan Uul IV and is a nearly complete postcranial skeleton lacking only the skull and neck. In 1977, this skeleton became the holotype of Opisthocoelicaudia skarzynskii. Nemegtosaurus and Opisthocoelicaudia were initially assigned to different sauropod higher taxa, Dicraeosaurinae and Camarasauridae respectively. However, since the late 1990s, both genera have been recognized as members of Titanosauria. Their coincident spatiotemporal distribution and non-overlapping skeletal parts have led to the persistent suspicion that they belong to the same species. Rediscovery of the original quarries and discovery of the postcranial remains attributable to the Nemegtosaurus holotype provides the first opportunity to directly compare these two taxa. Seven additional sites at the Nemegt locality preserve sauropod remains (including vertebrae, humeri, femora, pelvic elements, pedal phalanges, and unguals), and more than 20 sauropod footprint sites have been mapped. None of this material suggests that there is more than one sauropod taxon present in the Nemegt Formation. All localities occur within a discrete stratigraphic interval encompassing the uppermost Baruungoyot (footprints), Baruungoyot-Nemegt interfingering interval (Nemegtosaurus type), and lowermost Nemegt formations. Stratigraphic comparisons indicate the Opisthocoelicaudia locality at Altan Uul IV is within the lower beds of the Nemegt Formation. As sauropod remains are now documented for a total of 34 sites in the Nemegt Formation, a more refined stratigraphic framework may shed new light on the taxonomic inclusiveness of the sample.
\end{abstract}

\section{Introduction}

R. Gradziński discovered what became the holotype of the sauropod dinosaur Opisthocoelicaudia skarzynskii Borsuk Bialynicka, 1977 at Altan Uul IV in early June 1965. The huge excavation, which was undertaken between June 25th and July 7th, 1965, was complicated because it had been found on an elevated shelf of rock surrounded by deep canyons and even higher badlands (Kielan Jaworowska and Dovchin 1968). The closest the team could get vehicles to the site was more than half a kilometer, which meant that equipment, supplies, tools and fossils had to be carried or dragged by expedition members. Twelve tonnes of bone with the adhering hard sandstone were dragged on stone boats (made from empty fuel drums) to 'the Café', where they could be crated and loaded on trucks.

While that specimen was being excavated, a side trip to Nemegt led to the discovery of another sauropod. Kielan Jaworowska (1969, p. 115) recounted in her expedition narrative that Dovchin, Gradziński, Kuczyński, Maryańska and a driver left on June 15th for a two day fieldtrip to Nemegt. There, Kuczyński found a sauropod skull encased in the wall of one of the Nemegt canyons. They did not have the tools to remove more than a metre of dense sandstone above the skull. How ever, Walknowski drove another truck past the site a few days later en

\footnotetext{
* Corresponding author.

E-mail address: pjcurrie@ualberta.ca (P.J. Currie).
} 
route to Gurvan Tes. He took along Kuczyński the discoverer of the skull and Skarżyński so that they could excavate the skull. They re turned three days later with the skull cushioned by wood shavings in a spacious wooden box.

The unpublished field notes of Gradziński provide a little more information. Apparently, the members of the initial team left Altan Uul for Nemegt on June 15th at midday, Kuczyński discovered the skull on the 16th at midday, and they returned to Altan Uul IV on the 17th. The skull became the holotype of Nemegtosaurus mongoliensis Nowinski, 1971.

Opisthocoelicaudia skarzynskii is a nearly complete postcranial skeleton lacking only the skull and neck, whereas Nemegtosaurus mongoliensis is a skull and lower jaws that lack a postcranial skeleton. Nemegtosaurus and Opisthocoelicaudia were initially assigned to different sauropod subfamilies with vastly different tooth shapes, Dicraeosaurinae and Camarasauridae respectively. However, since the 1990s (Gimenez, 1992; Salgado and Calvo, 1992, 1997; Wilson and Sereno, 1998), both genera have been recognized as members of Tita nosauria. Their coincident spatiotemporal distribution and non over lapping skeletal parts have led to the persistent suspicion that they belong to the same species. The only way to determine if they are sy nonymous is to find a specimen that has skeletal parts that overlap both of the holotypes.

Here we report on recent field explorations that relocated the Opisthocoelicaudia quarry in 2007 and the Nemegtosaurus quarry in 2016. The Nemegtosaurus locality has produced additional bones that are compatible in size with the holotype skull of Nemegtosaurus and likely pertain to the same individual, providing the first opportunity to evaluate the relationship between Nemegtosaurus and Opisthocoelicaudia. Thirty two Nemegt sites (in addition to the holotype quarries, Table 1) preserve sauropod remains (including vertebrae, humeri, pelvic elements, femora, pedal phalanges, and unguals), and more than six sauropod footprint sites have been mapped (Stettner et al., 2017 this volume). These numbers do not include other sauropod material collected by the Soviet (Rozhdestvensky in Nowinski, 1971), Russian Mongolian (Kurzanov and Bannikov, 1983) and Polish Mon golian expeditions (Madzia and Borsuk Bialynicka, 2014). All localities occur within a discrete stratigraphic interval encompassing the upper most Baruungoyot (footprints), Baruungoyot Nemegt interfingering interval (Nemegtosaurus type), and lowermost Nemegt formations (Eberth, 2017, this volume; Fanti et al., 2017, this volume). Strati graphic comparisons indicate the Opisthocoelicaudia locality at Altan Uul IV is within the lower beds of the Nemegt Formation. Now that sauropod remains are documented for a total of 34 sites in the Nemegt Formation across the Nemegt Basin, a more refined stratigraphic fra mework may shed new light on the taxonomic inclusiveness of the sample.

\subsection{Institutional abbreviations}

MPC D, Institute of Paleontology and Geology of the Mongolian Academy of Sciences, Ulaan Baatar; ZPal, Palaeozoological Institute, Polish Academy of Sciences, Warsaw.

\section{Localities}

\subsection{Opisthocoelicaudia type locality}

The location of the quarry for the sauropod skeleton that ultimately became the holotype of Opisthocoelicaudia skarzynskii is marked on the map of Altan Uul IV (Gradziński et al., 1969, their Fig. 4). The hand drawn map was skillfully drawn through triangulation of cairns constructed at strategic points at Altan Uul IV. However, the small scale of the map made it impossible to relocate the quarry between 2006 and 2008. Fortunately, Gradziński was still alive at that time and provided additional information and photographs that led to the rediscovery of the quarry in 2009 (Currie, 2016). The excavation site was huge as would be expected for a sauropod quarry, but had been filled in by blowing sand. The infilling has made it impossible to determine if any additional bones of the holotype remain in the quarry. Nevertheless, the relocation of the quarry now permits a re evaluation of the stratigraphic level of the holotype. Gradziński et al. (1969, their Fig. 5) positioned the quarry high in the $75 \mathrm{~m}$ of Cretaceous fluvial strata at Altan Uul IV. Some taphonomic details of the specimen were provided by Gradziński (1970) and in the published quarry map (Borsuk Bialynicka, 1977, her Fig. 1). The specimen was initially housed at the Institute of Paleobiology (Warsaw), where it was catalogued as ZPAL MgD I/48. How ever, it was subsequently transferred to the Institute of Paleontology and Geology (Ulaan Baatar) where it has the catalogue number of MPC D100/404.

\subsection{Nemegtosaurus type locality}

Gradziński et al. (1969: their Fig. 2) provided the first map of the Nemegt locality that documented the primary quarries of the 1964 and 1965 expeditions. The figure caption of Gradziński et al. (1969: their Fig. 2) refers to an almost complete, $65 \mathrm{~cm}$ long sauropod skull marked on the map with the number 6 (Nem006 in Currie, 2016). The corresponding number on the map is located on the west side of Central Sayr near the mouth of a small sayr about $500 \mathrm{~m}$ to the northwest of the 1965 camp area (see Fanti et al., 2017, this volume). That specimen would later become the holotype of Nemegtosaurus mongoliensis (ZPal MgD I/9; Nowinski, 1971). Additional data on the stratigraphic oc currence, taphonomy, and completeness of this Nemegtosaurus in dividual were not available for more than 50 years after its discovery.

A systematic survey and relocation of stone cairns (used by the Polish geologists during mapping activities to triangulate points) near the Nemegtosaurus type area led to the fortuitous discovery of sauropod elements about $25 \mathrm{~m}$ from the estimated 'number 6' locality of Gradziński et al. (1969: their Fig. 2). Although we had attempted to find the quarry for more than eight years, we were in fact looking for it in the wrong place because the hand drawn maps had suggested it was in the adjacent sayr. No photographs have been relocated of the excava tion of the Nemegtosaurus skull, although a poor quality clip was found in a home movie taken by Gradziński in 1965 that seems to confirm that we have found the correct site. Several postcranial bones were re covered in 2016, mostly in situ, at the bottom of a steep cliff in the immediate vicinity of the Nemegtosaurus quarry (Figs. 1, 2, 3). These included a caudal centrum and a pedal ungual that were no longer in situ. The two ends of a right femur were found at the bottom of the sayr, but the shaft of the bone was found in situ in the cliff. In the same layer, an articulated tibia, fibula, and astragalus were found. The identity of the site was confirmed by discovery of quarrying material (plaster and burlap), packing material (wood shavings), and an empty can stamped with the same numbers as cans found in the 1965 Polish Mongolian camp. In addition, a small stone cairn commonly used during the Polish expeditions to mark important localities was found on top of the cliff directly facing the quarry. New, high resolution aerial photos acquired during the 2016 expedition provided accurate data for this location, documenting how remarkably accurate were the hand drawn maps of Gradziński and colleagues.

Measured sections at the site place in situ elements within a $2 \mathrm{~m}$ thick interval of red beds characterized by repeated centimeter to decimeter thick alternations of sandstone and siltstone layers (Figs. 2, 3). Despite overall tabular geometry of beds, load and water escape deformation are almost ubiquitous, suggesting high content of water in the sediment at the time of deposition. In addition, finer graded layers display evidence of early pedogenesis. Based on larger scale observation along the Nemegtosaurus sayr, this interval is interpreted as a splay washover area related to fluvial flood events. Facies analysis places the Nemegtosaurus quarry within the lowermost tongues of the Nemegt Formation. However, the section is representative of a stratigraphic 
Table 1

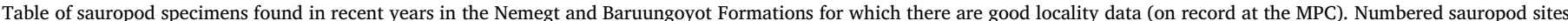

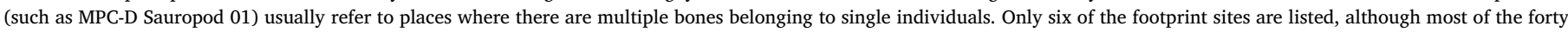

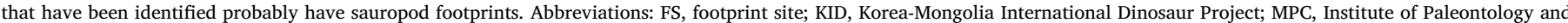

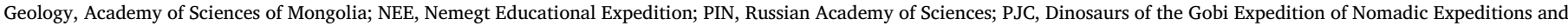
the MPC.

\begin{tabular}{|c|c|c|c|}
\hline Specimen \# & Site \# & Comment & Locality \\
\hline MPC-D100/401 & & Isolated femur & Nemegt \\
\hline MPC-D100/402 & & Skull, mandibles & Nemegt, Khadat tolgoi \\
\hline MPC-D100/404 (originally Zpal MgD-I/48) & & Holotype skeleton & Altan Uul 4 \\
\hline PIN $3906 / 2$ & & Holotype, partial skull & Shar Tsav \\
\hline ZPal MgD-I/9, MPC-D100/ & MPC-D Sauropod 34, Nem006 & Holotype skull & Nemegt, Central Sayr, 1965 \\
\hline ZPal MgD-I/25 & & Pectoral girdle & \\
\hline \multirow[t]{30}{*}{ MPC D100/406 } & MPC-D Sauropod 01 & Partial tail & Nemegt, West Sayr \\
\hline & MPC-D Sauropod 02 & & Altan Uul 4 \\
\hline & MPC-D Sauropod 03 & & Altan Uul 4 \\
\hline & MPC-D Sauropod 04 & & Altan Uul 4 \\
\hline & MPC-D Sauropod 05 & & Altan Uul 2 \\
\hline & MPC-D Sauropod 06 & & Guriliin Tsav \\
\hline & MPC-D Sauropod 07 & & Guriliin Tsav \\
\hline & MPC-D Sauropod 09 & Phalanges & Nemegt, North Sayr \\
\hline & MPC-D Sauropod 10 & & Ulaan Khushuu \\
\hline & MPC-D Sauropod 11 & & Nemegt, North Sayr \\
\hline & MPC-D Sauropod 12 & & Altan Uul 3 \\
\hline & MPC-D Sauropod 13 & & Nemegt, North Sayr \\
\hline & MPC-D Sauropod 14 & Partial skeleton (ribs, pelvis) & Nemegt, East Sayr \\
\hline & MPC-D Sauropod 15 & Vertebra & Nemegt, North Sayr \\
\hline & MPC-D Sauropod 16 & Eroded tail & Hermiin Tsav \\
\hline & MPC-D Sauropod 17 & & Hermiin Tsav \\
\hline & MPC-D Sauropod 18 & & Altan Uul 2 \\
\hline & MPC-D Sauropod 19 & Eroded partial skeleton & Bugiin Tsav \\
\hline & MPC-D Sauropod 20 & 15 articulated caudals & Bugiin Tsav \\
\hline & MPC-D Sauropod 21 & & Bugiin Tsav \\
\hline & MPC-D Sauropod 22 & Partial skeleton, 25 caudals & Altan Uul 2 \\
\hline & MPC-D Sauropod 23 & Sacrum, pelvis & Nemegt, North Sayr \\
\hline & MPC-D Sauropod 24 & Long bones & Altan Uul 2 \\
\hline & MPC-D Sauropod 25 & & Altan Uul 2 \\
\hline & MPC-D Sauropod 26 & & Altan Uul 2 \\
\hline & MPC-D Sauropod 27 & & Guriliin Tsav \\
\hline & MPC-D Sauropod 28 & & Guriliin Tsav \\
\hline & MPC-D Sauropod 29 & Partial skeleton & Bugeen Tsav \\
\hline & MPC-D Sauropod 30 & Caudals & Bugeen Tsav \\
\hline & MPC-D Sauropod 31 & & Tsagan Khushuu \\
\hline MPC-D PJC2012.070 & MPC-D Sauropod 32 & $\begin{array}{l}\text { Poached skeleton; Occipital condyle, alveoli, metacarpal, phalanx, } \\
\text { gastralia }\end{array}$ & Altan Uul 2 \\
\hline \multirow[t]{6}{*}{ MPC-D100F/015 } & MPC-D FS02, PJC2002.032 & Sauropod footprints & Nemegt, Central Sayr \\
\hline & MPC-D FS06 & Sauropod footprints & Nemegt, Central Sayr \\
\hline & MPC-D FS23 & Sauropod footprints & Nemegt, Central Sayr \\
\hline & MPC-D FS30 & Sauropod footprints & Nemegt, Central Sayr \\
\hline & MPC-D FS40 & Sauropod footprints & Nemegt, East Sayr \\
\hline & MPC-D FS43A & Sauropod footprints & Hermiin Tsav \\
\hline MPC-D KID005 & & Skin impression & Ulaan Khushuu \\
\hline MPC-D KID010 & & Tooth & Altan Uul 3 \\
\hline MPC-D KID060 & & Eggshell fragments & Altan Uul 1 \\
\hline MPC-D KID062 & & Tooth & Altan Uul 1 \\
\hline MPC-D KID076 & & Tooth & Altan Uul 3 \\
\hline MPC-D KID209 & & Tooth & Hermiin Tsav \\
\hline MPC-D KID210 & & Tooth & Hermiin Tsav \\
\hline MPC-D KID256 & & Tooth & Hermiin Tsav \\
\hline MPC-D KID284 & & Tooth & Hermiin Tsav \\
\hline MPC-D KID301 & & Unguals & Nemegt, North Sayr \\
\hline MPC-D KID315 & & Tooth & Hermiin Tsav \\
\hline MPC-D KID316 & & Tooth & Hermiin Tsav \\
\hline MPC-D KID352 & & Tarsal & Hermiin Tsav \\
\hline MPC-D KID387 & & Tooth & Hermiin Tsav \\
\hline MPC-D KID405 & & Tooth & Bugiin Tsav \\
\hline MPC-D KID425 & & Tooth & Bugiin Tsav \\
\hline MPC-D KID448 & MPC-D FS047 & Footprint & Bugiin Tsav \\
\hline MPC-D KID490 & & Tooth & Nemegt, South Monadnochs \\
\hline MPC-D KID502 & & Caudal vertebrae & Nemegt, North Sayr \\
\hline MPC-D KID505 & & Tooth & Altan Uul 2 \\
\hline MPC-D KID535 & & Ungual & Altan Uul 2 \\
\hline MPC-D KID557 & & Phalanx & Bugiin Tsav \\
\hline MPC-D KID599 & & Skin impression & Nogon Tsav \\
\hline MPC-D KID674 & & Posterior caudals & Khuree Tsav' \\
\hline MPC-D KID686 & & Footprints & Bugiin Tsav \\
\hline MPC-D NEE Sauropod coracoid & & Coracoid & $\begin{array}{l}\text { Nemegt, West Sayr } \\
\text { (continued on next pag }\end{array}$ \\
\hline
\end{tabular}




\begin{tabular}{|c|c|c|c|}
\hline Specimen \# & Site \# & Comment & Locality \\
\hline MPC-D NEE Sauropod squamosal & & Squamosal & Altan Uul 3 \\
\hline MPC-D PJC2000.019 & & Eggshell frags & Hermiin Tsav \\
\hline MPC-D PJC2000.030 & & Caudal vertebrae & Nemegt, Central Sayr \\
\hline MPC-D PJC2000.032 & & Ungual & Nemegt \\
\hline MPC-D PJC2002.034 & & Phalanx & Nemegt \\
\hline MPC-D PJC2003.001 & & & Nemegt \\
\hline MPC-D PJC2003.035 & & Skull or vertebral fragment & Nemegt \\
\hline MPC-D PJC2005.018 & & 2 unguals & Nemegt, North Sayr \\
\hline MPC-D PJC2006.021 & & Caudal vertebra, tooth marked & Nemegt \\
\hline MPC-D PJC2012.009 & & Skull fragment & Nemegt, North Sayr \\
\hline MPC-D Hayashibara 060823 BgT-II BD & & 2006 report & Bugin Tsav II \\
\hline MPC-D Hayashibara 060829 AU-IV TSI & & Cervical vertebra, 2006 report & Altan Uul 4 \\
\hline MPC-D Hayashibara 080926 KmK KHB & & Skull, 2008 report & Khamaryn Khural \\
\hline
\end{tabular}

interval of approximately $2025 \mathrm{~m}$ in which the Nemegt Formation includes recurrent tongues of the Baruungoyot Formation (Eberth et al., 2009; Eberth, 2017, this volume; Fanti et al., 2012; Fanti et al., 2017, this volume) that crop out in the proximity of the quarry.

\section{Systematic paleontology}

DINOSAURIA Owen, 1842

SAUROPODA Marsh, 1878

MACRONARIA Wilson and Sereno, 1998

TITANOSAURIA Bonaparte and Coria, 1993

NEMEGTOSAURIDAE Upchurch, 1995

NEMEGTOSAURUS Nowinski, 1971

\subsection{Type species}

Nemegtosaurus mongoliensis Nowinski, 1971

\subsection{Holotype}

ZPal MgD I/9 (holotype), nearly complete skull and lower jaws lacking only parts of the narial region and palate, prearticular and articular (Nowinski, 1971; Wilson, 2005). In this paper, we augment the holotype with postcranial material that includes a caudal centrum, right femur, tibia, fibula, astragalus, and pedal ungual, all registered as MPC D100/413.

\subsection{Referred specimens}

MPC D100/402 (Maryańska, 2000) is a nearly complete skull with lower jaws that was found and collected in 1974 by B. Namsrai from the Nemegt locality at Khadat Tolgoi. Although it appears morphologically to be Nemegtosaurus (the preantorbital fenestra is lying in a conspicuous fossa, although only the anterior margin is preserved), the specimen has still not been properly studied or described.

\subsection{Type locality and horizon}

Central Sayr, Nemegt Locality (sensu Gradziński et al., 1969), $43^{\circ} 30^{\prime}$ $6.06^{\prime \prime} \mathrm{N}, 101^{\circ} 2^{\prime} 54.26^{\prime \prime} \mathrm{E}$. Nemegt Formation, lower tongues within the interfingering interval with the Baruungoyot Formation (see Eberth, 2017 this volume and Fanti et al., 2017 this volume).

\subsection{Diagnosis (Wilson, 2005)}

Autapomorphies of Nemegtosaurus mongoliensis include presence of a spur on the posterior edge of the squamosal and the preantorbital fenestra lying in a conspicuous fossa. Ambiguous autapomorphies are features that cannot be scored in Quaesitosaurus and other closely related taxa, such as the presence of an accessory fenestra (anterodorsal to the preantorbital fenestra), a jugal foramen, and a coronoid foramen.

\section{Description}

Only the bones recovered during the 2016 field season will be described in this paper. Although more of the specimen will be recovered
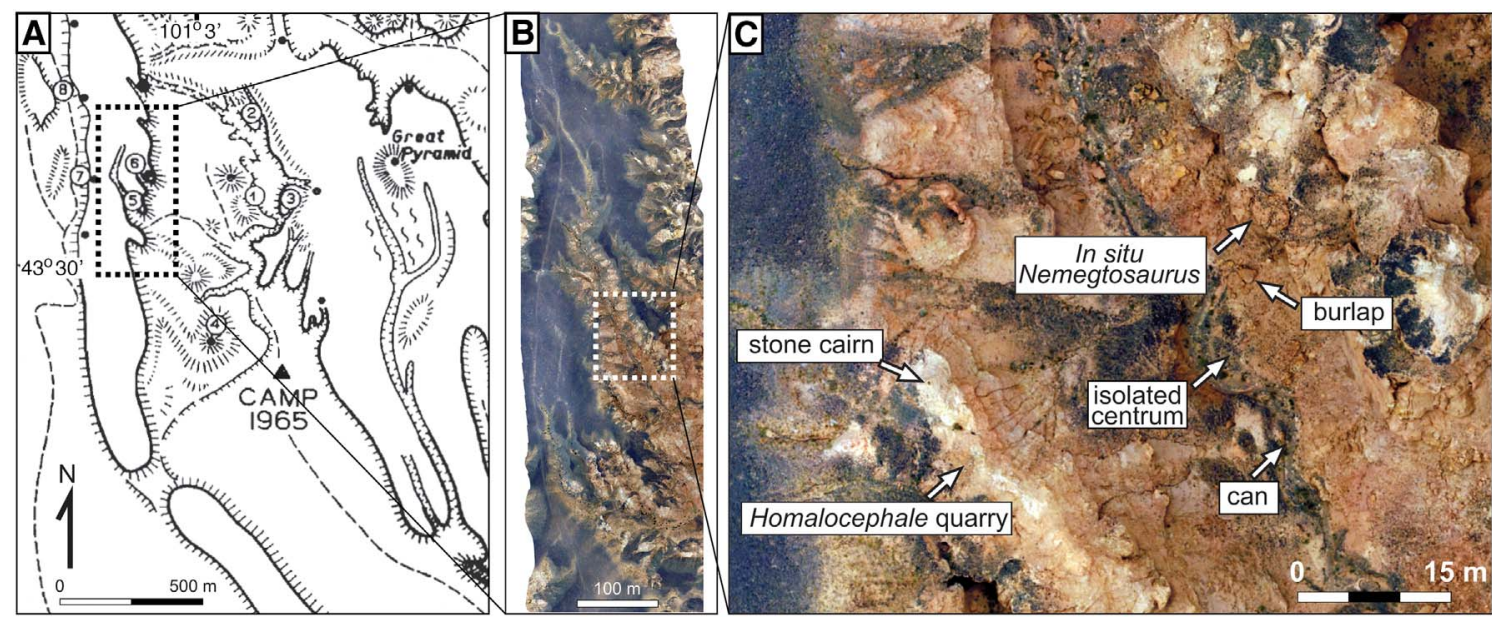

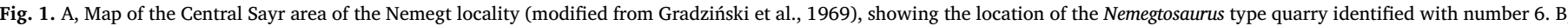

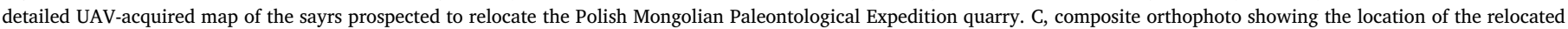
Nemegtosaurus type quarry and other features discussed in this manuscript. 

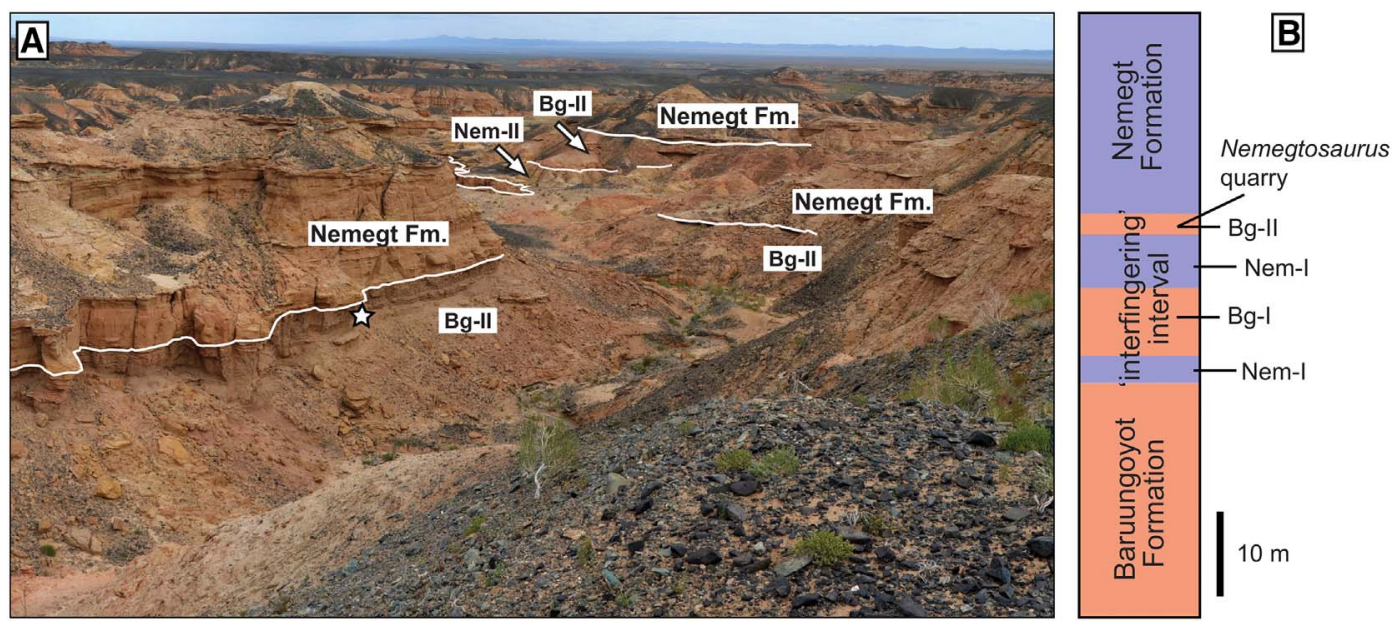

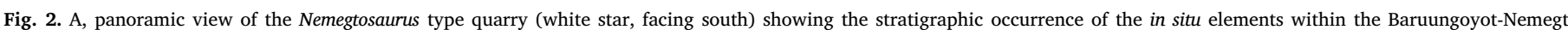

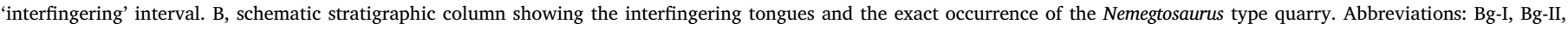
interfingering tongues of the upper part of the Baruungoyot Formation; Nem-I, Nem-II, interfingering tongues of the lower part of the Nemegt Formation.

when funds become available, it is unlikely to be done until 2018. A caudal centrum, femur, tibia, fibula, astragalus, and pedal ungual were found at the site that produced the holotypic skull of Nemegtosaurus mongoliensis in 1965, and presumably belong to the same individual.

The centrum (Figs. 4, 5, 6) seems to be from either a sacral or proximal caudal vertebra. It is clearly opisthocoelous, which is the feature for which the genus was named originally. Note that although the ventral edge of the intervertebral articulation seems to be deeply emarginated (Fig. 5F) on the midline, this is because the edge is damaged and has been restored conservatively (Fig. 6B). The centrum is wider $(27 \mathrm{~cm})$ than tall $(19 \mathrm{~cm})$, and relatively short $(10 \mathrm{~cm}$, excluding the ball), which are similar proportions to those of the sixth sacral
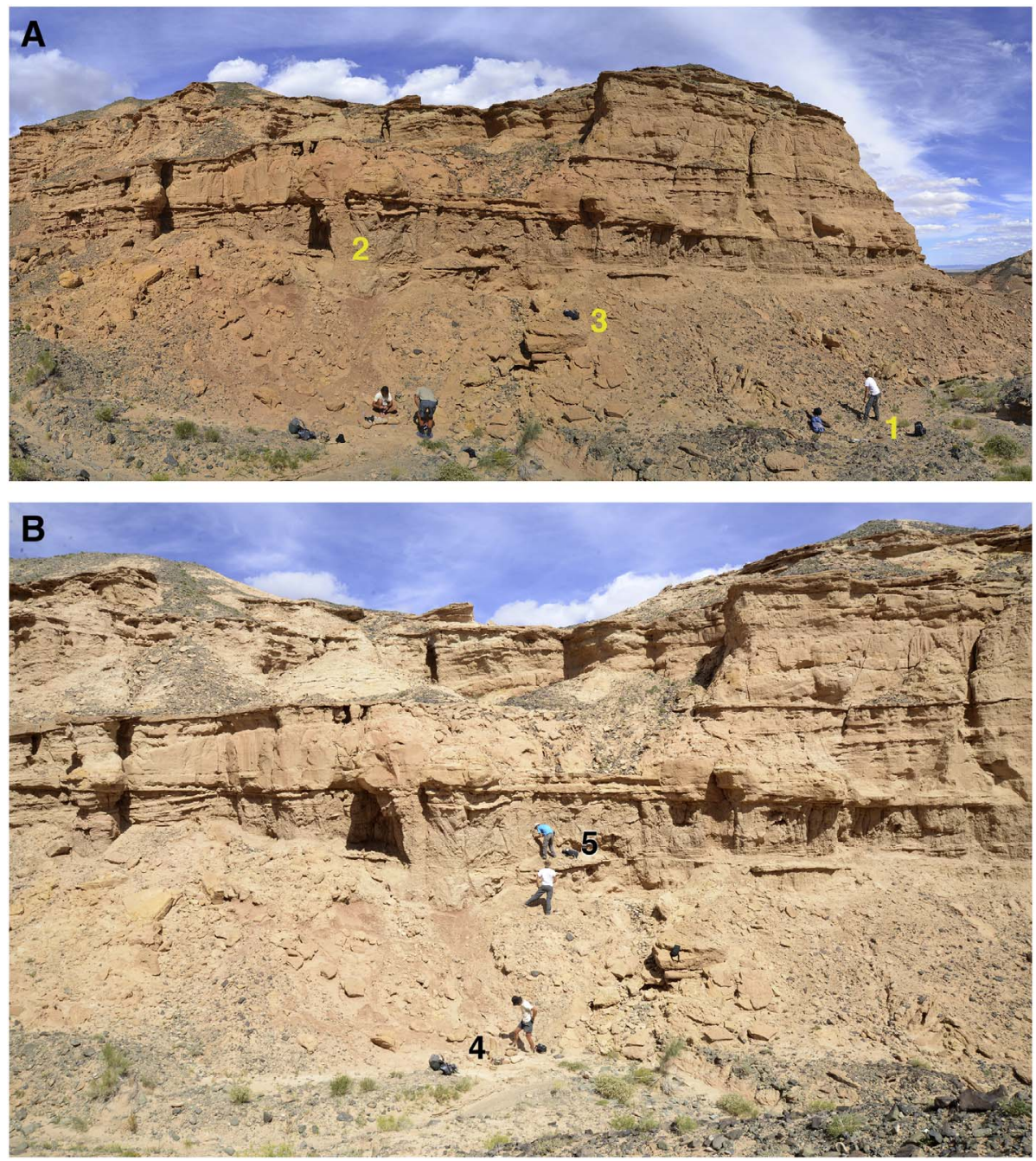

Fig. 3. A) Panoramic view of cliff face that contains the Nemegtosaurus quarry. Eroded bones and the Polish tin can were found on the sayr floor towards the right (1), in situ bones were found in the cliff (2) above the person on the left, and packing material (wood shavings) was found on the talus slope (3) next to the big rock with the packsack on top. B). Closer view of Nemegtosaurus quarry. Ends of femur (4) were found at the feet of the person with the white shirt to the left, while the shaft was recovered from the shelf at the feet of the person in a blue shirt. (For interpretation of the references to color in this figure legend, the reader is referred to the web version of this article.) 


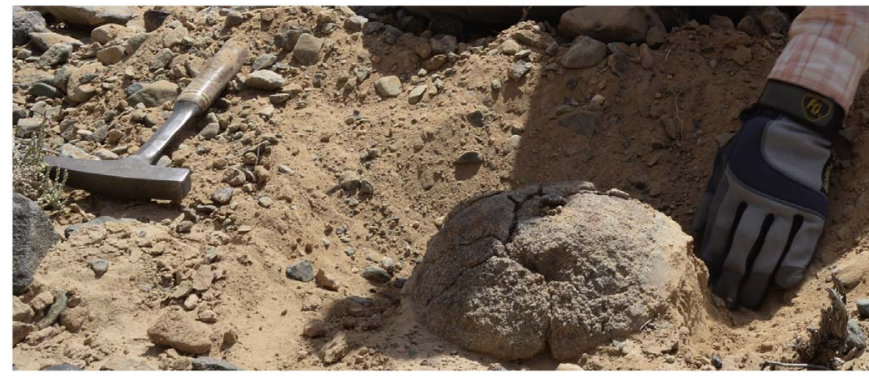

Fig. 4. Opisthocoelous caudal centrum (MPC-D100/413) as found at the bottom of the talus slope.

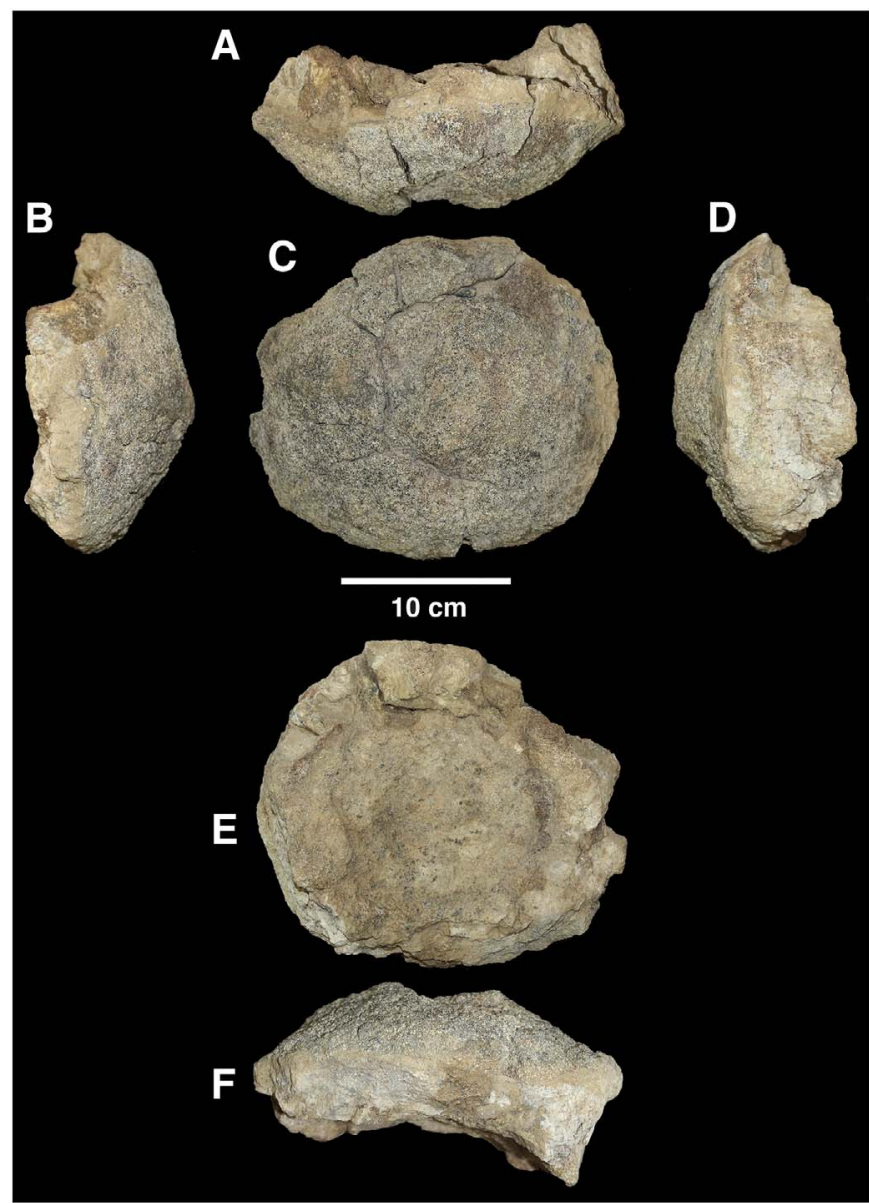

Fig. 5. Opisthocoelous caudal centrum (MPC-D100/413) in dorsal (A), right lateral (B), anterior (C), left lateral (D), posterior (E) and ventral (F) views.

centrum of Rapetosaurus (Curry Rogers, 2009). The identification as an anterior caudal is more likely because the posterior width is only $82 \%$ of the anterior width of the centrum. The measurements are slightly smaller than the same ones in the anterior sacral and anterior caudal vertebrae of Opisthocoelicaudia (Borsuk Bialynicka, 1977, Tables 2, 3), in which the same dimensions are $28 \mathrm{~cm}, 24 \mathrm{~cm}$ and $12 \mathrm{~cm}$ in the first caudal vertebra. The dorsal surface, which is badly damaged, is marked on the left side by deep, anteroposteriorly oriented pits and ridges. However, it is impossible to tell if these were for contact with the unfused neural arch, or if they are just broken bone surfaces. If the neural arch had not fused by the time of death, this would suggest that the animal was not fully mature. Footprints from Nemegt suggest the presence in the area of sauropod individuals that were much larger than the holotypes of Nemegtosaurus and Opisthocoelicaudia (Nakajima et al., 2017, this volume; Stettner et al., 2017, this volume), indicating that

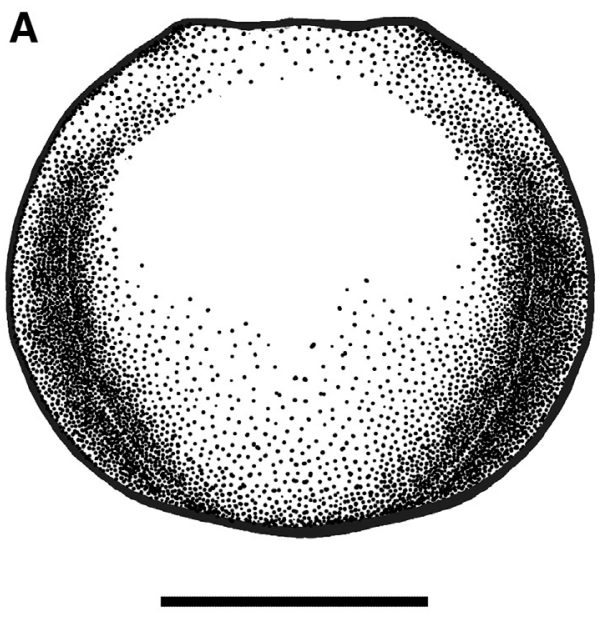

$10 \mathrm{~cm}$

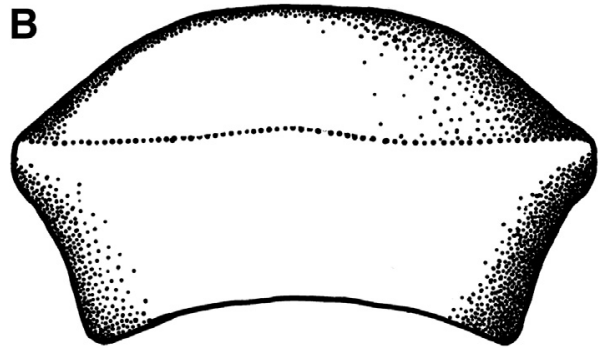

Fig. 6. Restored anterior (A) and ventral (B) views of MPC-D100/413.

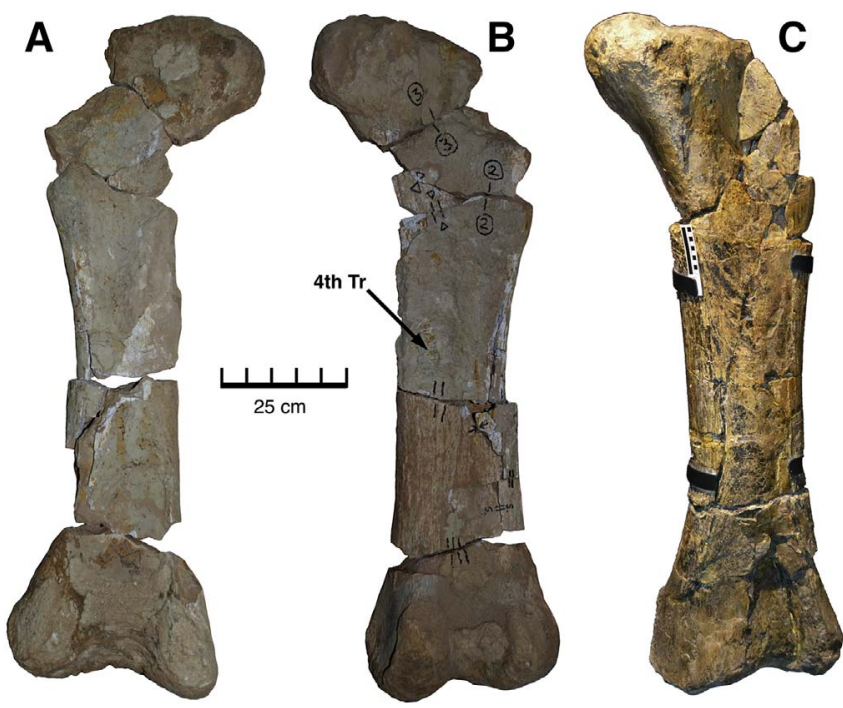

Fig. 7. Femora of Nemegtosaurus (MPC-D100/413) (A, B) and Opisthocoelicaudia (MPC D100/404) (C) in anterior (A, C) and posterior (B) views. Abbreviation: 4th $\mathrm{Tr}$, fourth trochanter.

MPC D100/413 is relatively small. Similar to Opisthocoelicaudia (Borsuk Bialynicka, 1977) but unlike Rapetosaurus (Curry Rogers, 2009), there is no evidence of lateral pneumatopores.

The right femur (Figs. 7A, B, 8) is $124 \mathrm{~cm}$ long, which is approximately $11 \%$ shorter than the length of the femur of the holotype (MPC D100/404) of Opisthocoelicaudia. The surfaces of both articular ends are strongly rugose (Fig. 8), which in other dinosaur taxa would suggest that this individual was approaching maturity. However, this does not appear to be the case in sauropods, which typically have weight bearing limb bones with rugose ends from young ages. Furthermore, the femur 


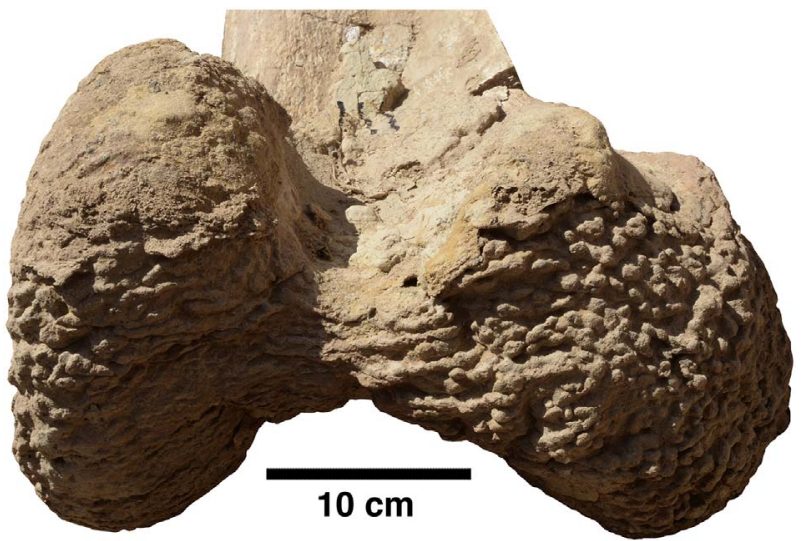

Fig. 8. Distal end of right femur showing the rugose texture characteristic of the ends of the limb bones.

is almost 20\% shorter than MPC D100/401 an isolated sauropod femur from the Nemegt Formation and as previously mentioned, footprints suggest that sauropods became much larger than known skeletal material (Nakajima et al., 2017 this volume; Stettner et al., 2017 this volume). The convex head of the femur is oriented dor somedially above the level of the greater trochanter, and the articula tion for the acetabulum is oriented dorsally as in other titanosaurs (Curry Rogers, 2009). Like the holotype of Opisthocoelicaudia and other titanosaurs (Curry Rogers, 2009), the shaft is flattened ante roposteriorly so that the transverse diameter is around $185 \%$ the anteroposterior diameter. A flange extends along the lateral surface of the proximal half of the femur. The shaft has a minimum circumference of $60 \mathrm{~cm}$, compared with $68 \mathrm{~cm}$ in MPC D100/404 and $75 \mathrm{~cm}$ in MPC D100/401. The fourth trochanter is a low, $810 \mathrm{~cm}$ long ridge close to the middle of the bone on the posterior (flexor) surface. The centre of the trochanter is almost exactly midlength of the femur, whereas it is somewhat distal to midlength in the holotype of Opisthocoelicaudia skarzynskii (Borsuk Bialynicka, 1977). The medial (tibial) condyle of the distal end is a prominent, semicircular articulation that extends anteriorly and posteriorly well beyond the combined lateral and fibular condyle (Fig. 8).

Only the distal ends of the articulated right tibia and fibula (Fig. 9) can be seen at present, because their shafts and proximal ends are buried deep in a vertical sandstone cliff. The distal articular end of the tibia is deeply rugose, and measures $28.5 \mathrm{~cm}$ in width (compared with $29.8 \mathrm{~cm}$ in Opisthocoelicaudia; note that this was measured from the specimens and disagrees with the $20 \mathrm{~cm}$ width attributed to the distal end of the tibia by Borsuk Bialynicka, 1977), and a maximum of $14.5 \mathrm{~cm}$ in anteroposterior length.

The distal end of the fibula (Fig. 9C, D) is closely appressed to the anterolateral corner of the tibia and has a maximum anteromedial to posterolateral width of $15.5 \mathrm{~cm}$ (compared with $16 \mathrm{~cm}$ in MPC D100/ 404).

The right astragalus was found in articulation with the distal ends of the right tibia and fibula (Fig. 9A, B). Similar to Opisthocoelicaudia (Borsuk Bialynicka, 1977; Wilson, 2002) and other titanosaurs for which the lower leg is preserved (González Riga et al., 2016), there is no evidence that there were any other ossified tarsals. It covered most of the distal end of the fibula and about half of the tibia (Fig. 9B). The anteroventral surface is strongly curved and rugose, and it would have directly contacted the lateral metatarsals as in Opisthocoelicaudia. When it was initially removed, a thin, low ascending process with a triangular cross section was left between the distal ends of the tibia and fibula (Fig. 9C, D). The ascending process is comparable in size to that of Opisthocoelicaudia (Borsuk Bialynicka, 1977, her pl. XXIV, Fig. 2b), al though the body of the astragalus seems to have been positioned more laterally in Nemegtosaurus. This can of course be because of post
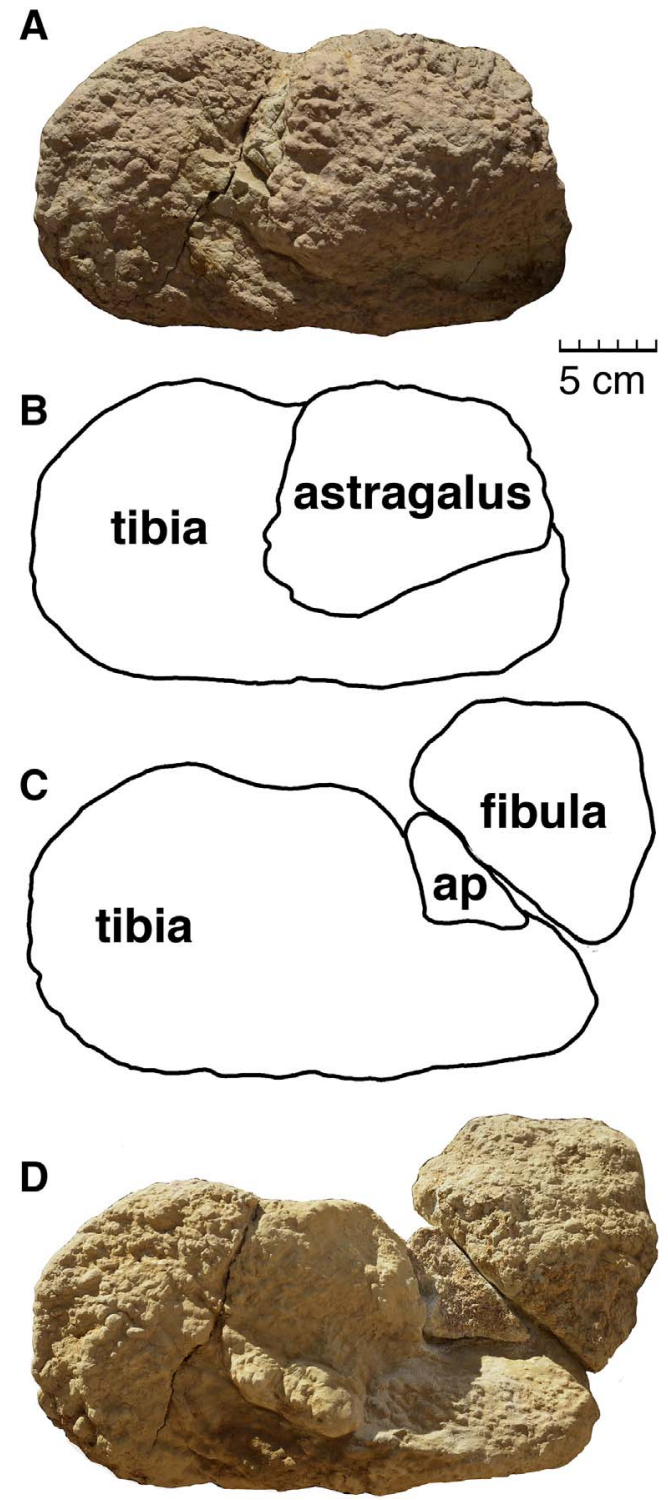

Fig. 9. A, B) distal view of in situ, articulated right tibia and astragalus (MPC-D100/413). C, D) same view but main body of the astragalus has been removed to expose the ascending process (ap) of the astragalus and the distal end of the fibula.

mortem taphonomic processes. However, it is unlikely to have shifted far because of the presence of the ascending process wedged between the tibia and fibula. The fact that the astragalus extends to the lateral edge of the distal end of the fibula clearly shows that there was no calcaneum. The astragalus is $15 \mathrm{~cm}$ wide and $12.7 \mathrm{~cm}$ ante roposteriorly, compared with $17 \mathrm{~cm}$ and $14 \mathrm{~cm}$ in the holotype of Opisthocoelicaudia (Borsuk Bialynicka, 1977).

A single ungual (Fig. 10G) was found downslope from the in situ Nemegtosaurus postcranial bones. Two other unguals (Fig. 10A F) were found together (but without any association with other sauropod bones) several kilometres away in Northern Sayr, but they clearly represent another titanosaurid individual. They are subequal in size, which is one of the characters used to diagnose Opisthocoelicaudia (Wilson, 2002). All are mediolaterally compressed, although the outer surface is inclined dorsomedially in relation to the roughly horizontal ventral surface. They are nearly identical with pedal unguals recovered with the holotype of Opisthocoelicaudia (Borsuk Bialynicka, 1977), as well as several described by Madzia and Borsuk Bialynicka (2014). 


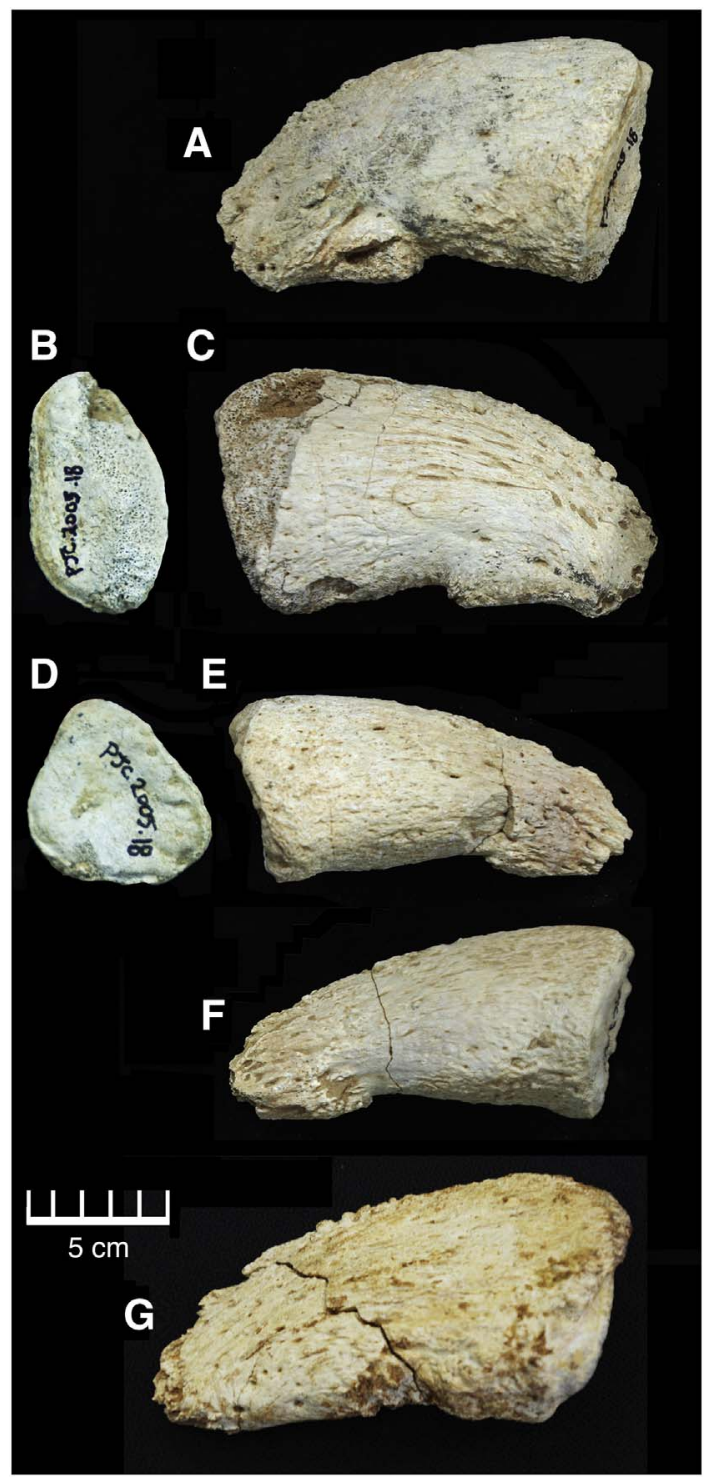

Fig. 10. Pedal unguals of $c f$. Nemegtosaurus in lateral (A, F, G), medial (C, E) and proximal (B, D) views. A-F, MPC-D PJC2005.18. G) MPC-D100/413.

\section{Discussion}

Although they are less common than those of theropods and hadrosaurs, sauropod remains such as isolated teeth, postcranial elements and footprints are now known from multiple localities in the Nemegt Formation, including Altan Uul II, III and IV, Hermiin Tsav II, Nemegt, Tsagaan Khushuu, and Ulaan Khushuu (Table 1).

At the time of writing, eight sites within the Nemegt locality preserve sauropod remains (one in the Western Sayr, two in the Central Sayr, five in the Northern Sayr), and more than six sauropod footprint sites have been identified. An additional 24 sauropod sites have been found at other Nemegt Formation localities. The stratigraphic range of these localities (including the holotypes of Nemegtosaurus mongoliensis and Opisthocoelicaudia skarzynskii, a partial skeleton discovered in 2002, and the vast majority of tracks) is from the Baruungoyot Nemegt transition to the lower $80 \mathrm{~m}$ of the Nemegt Formation (Table 1). As such, this study provides evidence that Nemegtosaurus can be added to the list of taxa that co existed at the time of deposition of the Bar uungoyot Nemegt transition, including Avimimus, Ingenia, Nemegtomaia, and Tarchia (Fanti et al., 2012).

Although more than 70 titanosaur genera are known, less than one quarter of these are known from cranial remains and only four are known from complete skulls (Nemegtosaurus, Rapetosaurus, Sarmientosaurus, Tapuiasaurus). Very few titanosaurs are known from complete vertebral columns, and associations between cranial and postcranial remains are rare. As a consequence, the interrelationships of the group remain poorly resolved, although recent efforts have begun to improve this situation (e.g., Díez Díaz et al., 2016; Gorscak and O'Connor, 2016). Nevertheless, lack of morphological overlap between closely related titanosaur taxa, such as is the case with Nemegtosaurus and Opisthocoelicaudia, remains a difficult issue to resolve (Wilson et al., 2016).

Borsuk Bialynicka (1977) argued for the generic separation of $\mathrm{Ne}$ megtosaurus and Opisthocoelicaudia on the grounds that there is high generic diversity of sauropods within single formations in other parts of the world. Although this may be the case in certain taxa within certain formations (e.g., Morrison, Tendaguru), it does not appear to characterize the Nemegt Formation. In spite of its diversity of dinosaurs, there are relatively few species within any of the families represented by large animals, which suggests a stressed environment, probably with a relatively restricted geographic area. There are no ceratopsids in the Nemegt Formation, and there could be as few as one species of hadrosaurid (Saurolophus angustirostris, which may be the senior synonym of Barsboldia sicinskii). Much of the diversity of large herbivores is composed of large herbivorous theropods like Deinocheirus and Ther izinosaurus. Compare this with the Dinosaur Park Formation (Currie and Koppelhus, 2005), which has high species diversity of large herbivorous animals such as ankylosaurids, ceratopsids, hadrosaurids and nodosaurids. Thus, there is clearly something fundamentally different between the ecosystems of the Dinosaur Park and Nemegt formations.

Where previously there was no morphological overlap between Nemegtosaurus mongoliensis and Opisthocoelicaudia skarzynskii, now there are several overlapping postcranial bones that can be compared. Our preliminary results were not able to identify significant differences in size or morphology between these two individuals. Significantly, one of the few characters originally used to diagnose Opisthocoelicaudia is the presence of opisthocoelus vertebrae, which is now also known in Nemegtosaurus. This has been considered an autapomorphic character for Opisthocoelicaudia (Wilson, 2002), which clearly shows that $\mathrm{Ne}$ megtosaurus and Opisthocoelicaudia are closely related, perhaps as sister taxa. Both Nemegtosaurus mongoliensis and Opisthocoelicaudia skarzynskii lack a calcaneum, but this feature is present in other titanosaurs (González Riga et al., 2016).

This is also the case with isolated teeth and postcranial remains from the same formation (Table 1), which do not appear to differ significantly from one another. This led Madzia and Borsuk Bialynicka (2014) to speculate that Opisthocoelicaudia skarzynskii is a junior synonym of Nemegtosaurus mongoliensis. This leads us to suspect that there is no more than a single sauropod species in the Nemegt Formation. Additional support for this hypothesis comes from the spatiotemporal distribution of these sauropod fossils, which are concentrated close to the interface between the Baruungoyot and Nemegt Formations, and probably represent a single ecosystem spanning a limited time period.

A pair of unguals (Fig. 10A D) found about two kilometres from the Nemegtosaurus mongoliensis holotype locality are subequal in size. These are morphologically similar to the ungual found in the Nemegtosaurus quarry, but are also similar to other titanosaur unguals. However, Opisthocoelicaudia is distinct from other titanosaurs in that the second pedal ungual is not significantly different in size from the first. If the pair of claws are identified as Opisthocoelicaudia on the basis of their relative size, then they show that this genus is found in geographically the same area (at the same general level stratigraphically) as Ne megtosaurus. The sauropod footprints (Currie et al., 2003; Nakajima et al., 2017 this volume; Stettner et al., 2017 this volume) from the Nemegt locality also suggest that the claws on the first and second digits were equally well developed. This character can be used to support the idea that either the sauropod at Nemegt is Opisthocoelicaudia, or that 
Nemegtosaurus also shares this character, or that the two animals are synonymous.

\section{Conclusions}

Relocation of the quarries of the holotypes of Nemegtosaurus mon goliensis and Opisthocoelicaudia skarzynskii has led to the discovery of additional bones of Nemegtosaurus that allow for the first time direct morphological comparison between the two species. Currently, these include one caudal centrum, a femur, the distal ends of the tibia and fibula (both of which are still in situ in the field), an astragalus, and a pedal ungual. Each of these bones is very similar to corresponding elements in Opisthocoelicaudia skarzynskii. The opisthocoelous caudal centrum is diagnostic of Opisthocoelicaudia, and its shared presence in Nemegtosaurus suggests the two taxa are closely related, possibly even synonymous. However, caution leads us to wait until more of the holotypic skeleton of Nemegtosaurus mongoliensis is excavated sometime in the foreseeable future.

\section{Acknowledgments}

Relocation of the Polish Mongolian Paleontological Expedition quarries has only been possible because of the maps that were produced by R. Gradziński, T. Jerzykiewicz, and various people who assisted them. The Opisthocoelicaudia quarry was relocated in 2009 after R. Gradziński provided detailed notes, photographs and sketches to PJC. The Nemegtosaurus holotype quarry was not rediscovered until after Gradziński had passed away, but finding a means to confirm its discovery would not have been possible without the help of his son (Dr. M. Gradziński) and W. Skarzynski who searched through photographs and film footage, and old field notes for anything that might be useful. We are extremely grateful for their help and support. Additional data on Rapetosaurus vertebrae were provided by K. Curry Rogers, and her willingness to share unpublished information is appreciated. Appreciation is also extended to Editor in Chief Prof. T. Algeo and two anonymous reviewers. Fieldwork for this project was funded by the National Geographic Society/Waitts Grant Program (grant \#W434 16), by the Sistema Museale di Ateneo, University of Bologna, and by an NSERC (grant \#2016 04674) grant to the first author.

\section{References}

Borsuk-Bialynicka, M., 1977. A new camarasaurid sauropod Opisthocoelicaudia skar$1-64$. zynskii, gen. n., sp. n. from the Upper Cretaceous of Mongolia. Palaeontol. Pol. 37,

Currie, P.J., 2016. Dinosaurs of the Gobi: following in the footsteps of the PolishMongolian Expeditions. Palaeontol. Pol. 67, 83-100.

Currie, P.J., Koppelhus, E.B., 2005. Dinosaur Provincial Park, a Spectacular Ancient Ecosystem Revealed. Indiana University Press, Bloomington, Indiana, pp. 648.

Currie, P.J., Badamgarav, D., Koppelhus, E.B., 2003. The first Late Cretaceous footprints from the Nemegt locality in the Gobi of Mongolia. Ichnos 10, 1-13. http://dx.doi. org $/ 10.1080 / 10420940390235071$.

Curry Rogers, K., 2009. The postcranial osteology of Rapetosaurus krausei (Sauropoda: Titanosauria) from the Late Cretaceous of Madagascar. J. Vertebr. Paleontol. 29,
1046-1086.

Díez Díaz, V., Mocho, P., Páramo, A., Escaso, F., Marcos-Fernández, F., Sanz, J.L., Ortega, F., 2016. A new titanosaur (Dinosauria, Sauropoda) from the Upper Cretaceous of Lo Hueco (Cuenca, Spain). Cretac. Res. 68, 49-60.

Eberth, D.A., 2017. Stratigraphy and paleoenvironmental evolution of the dinosaur-rich Baruungoyot-Nemegt succession (Upper Cretaceous), Nemegt Basin, southern Mongolia. Palaeogeogr. Palaeoclimatol. Palaeoecol. XX-XX (this volume).

Eberth, D.A., Badamgarav, D., Currie, P.J., 2009. The Baruungoyot-Nemegt transition (Upper Cretaceous) at the Nemegt type area, Nemegt Basin, south central Mongolia. J. Paleontol. Soc. Korea 25 (1), 1-15.

Fanti, F., Currie, P.J., Badamgarav, D., 2012. New specimens of Nemegtomaia from the Baruungoyot and Nemegt formations (Late Cretaceous) of Mongolia. PLoS ONE 7 (2), e31330. http://dx.doi.org/10.1371/journal.pone.0031330.

Fanti, F., Cantelli, L., Angelicola, L., 2017. High-resolution maps of Khulsand and Nemegt localities (Nemegt Basin, southern Mongolia): stratigraphic implications. Palaeogeogr. Palaeoclimatol. Palaeoecol. XX-XX (this volume).

Gimenez, O., 1992. Estudio preliminar del miembro anterior de los sauropodos titanosauridos. Ameghiniana 30, 154 (Abstract).

González Riga, B.J., Lamanna, M.C., Ortiz David, L.D., Calvo, J.O., Coria, J.P., 2016. A gigantic new dinosaur from Argentina and the evolution of the sauropod hind foot.

Sci. Rep. 6, 19165. http://dx.doi.org/10.1038/srep19165.

Gorscak, E., O'Connor, P.M., 2016. Time-calibrated models support congruency between Cretaceous continental rifting and titanosaurian evolutionary history. Biol. Lett. 12, 20151047.

Gradziński, R., 1970. Sedimentation of dinosaur-bearing Upper Cretaceous deposits of the Nemegt Basin, Gobi Desert. Palaeontol. Pol. 21, 147-229.

Gradziński, R., Kazmierczak, J., Lefeld, J., 1969. Geographical and geological data from the Polish-Mongolian Palaeontological Expedition. In: Palaeonto Gradziński Logia

Polonica. 19. pp. 33-80.

Kielan-Jaworowska, Z., 1969. Hunting for Dinosaurs. MIT Press, Cambridge, MA (177 pp. [Translated from the Polish]).

Kielan-Jaworowska, Z., Dovchin, N., 1968-1969. Narrative of the Polish-Mongolian palaeontological expeditions 1963-1965. Palaeontol. Pol. 19, 7-30.

Kurzanov, S.M., Bannikov, A.F., 1983. A new sauropod from the Upper Cretaceous of Mongolia. Palaeontol. J. 2, 91-97.

Madzia, D., Borsuk-Bialynicka, M., 2014. New sauropod material from the Nemegt Formation supports the conspecificity of Opisthocoelicaudia skarzynskii and Nemegtosaurus mongoliensis (Sauropoda, Titanosauria). J. Vertebr. Paleontol. 2014, 173-174 (Program And Abstracts).

Maryańska, T., 2000. Sauropods from Mongolia and the former Soviet Union. In: Benton, M.J., Shishkin, M.A., Unwin, D.M., Kurochkin, E.N. (Eds.), The Age of Dinosaurs in Russia and Mongolia. Cambridge University Press, Cambridge, pp. 456-461.

Nakajima, J., Kobayashi, Y., Chinzorig, Tlk, Tanaka, T., Takasaki, R., Tsogtbaatar, K., Currie, P.J., 2017. Dinosaur tracks at the Nemegt locality: paleobiological and paleoenvironmental implications. Palaeogeogr. Palaeoclimatol. Palaeoecol. XX-XX (this volume).

Nowinski, A., 1971. Nemegtosaurus mongoliensis n. gen., n. sp., (Sauropoda) from the uppermost Cretaceous of Mongolia. Palaeontol. Pol. 25, 57-81.

Salgado, L., Calvo, J.O., 1992. Cranial osteology of Amargasaurus cazaui Salgado and Bonaparte (Sauropoda, Dicraeosauridae) from the Neocomian of Argentina. Ameghiniana 29, 337-346.

Salgado, L., Calvo, J.O., 1997. Evolution of titanosaurid sauropods. II: the cranial evidence. Ameghiniana 34, 33-48.

Stettner, B., Persons IV, W.S., Currie, P.J., 2017. A giant sauropod footprint from the Nemegt Formation (Upper Cretaceous) of Mongolia. Palaeogeogr. Palaeoclimatol. Palaeoecol. XX-XX (this volume).

Wilson, J.A., 2002. Sauropod dinosaur phylogeny: critique and cladistic analysis. Zool. J. Linnean Soc. 136, 217-276.

Wilson, J.A., 2005. Redescription of the Mongolian sauropod Nemegtosaurus mongoliensis Nowinski (Dinosauria: Saurischia) and comments on Late Cretaceous sauropod diversity. J. Syst. Palaeontol. 3, 283-318.

Wilson, J.A., Sereno, P.C., 1998. Early Evolution and Higher-level Phylogeny of Sauropod Dinosaurs. 5. Society of Vertebrate Paleontology Memoir, pp. 1-68 (Supplement to the Journal of Vertebrate Paleontology 18).

Wilson, J.A., Pol, D., Carvalho, A.B., Zaher, H., 2016. The skull of the titanosaur Tapuiasaurus macedoi (Dinosauria: Sauropoda), a basal titanosaur from the Lower Cretaceous of Brazil. Zool. J. Linnean Soc. 178 (3), 611-662. 